\title{
VOTING SYSTEM USING ANDROID OPERATING SYSTEM
}

\author{
SYED ALI HASSAN $^{1}$, MOHSIN ANWAR ${ }_{2}$ \\ ${ }^{1}$ Department of Computer Sciences, University of Management and Technology, Lahore, Pakistan \\ ${ }^{2}$ Department of Computer Sciences, University of Management and Technology, Lahore, Pakistan \\ Email: $\left\{\right.$ F2017108005 ${ }^{1}$, F2017108016 $\} @$ umt.edu.pk
}

\begin{abstract}
In the normal ballot process, voting condition is troublesome in light of dislike of voters to go for voting to polling stations coming from far places, stay in long queues and sit tight drawn out for their turn. A couple of individuals settle on wrong decision which cause star choice issues. This customary strategy for voting can be switched to a more progressive and beneficial approach entitle Mobile-Voting system. We propose wonderful, essential and organized way to deal with vote, shedding the insufficiencies of regular approach. By using the customer id and mystery word against one CNIC, one voter can settle on one decision. If one person has the right to vote then a voting structure is displayed to him and approval is finished by using One Time Password (OTP) rule, thumb impression and face affirmation. Advancement of technology can be used to provide benefit to the people who vote but face difficulties during this process. To give permission of utilization of this right, all over the world where the voting through mobile is conducting have some common steps like voter verification and confirmation, counting and checking of votes, announcement of result. In the proposed system each voter is affirmed by the CNIC, OTP, thumb impression and face affirmation. Each vote caste against a candidate is placed in the database for the individual dispute. At end of the ballot casting system the counter checks the total ballot caste against each candidate and makes a short report of it and give it to the admin. Admin have access to share these results with everyone who have the ballot casting application.
\end{abstract}

Keywords: GSM; Queues; Android operating system; CMOS.

1. Introduction. The world is dependably in changed in the forefront and in headway that is the reason we should continue running by each other with it, to be fit as much as we can get advantage from these changes. Voting in favor of any social issue is key for present days. Social demands on solving the vote casting issue increases step by step. So it is twisting up remarkably fundamental to affect the voting to process all the more essential and convincing. Of course the speedy change in working approach moves to the functional movement on the tremendous extend. The administrator purpose behind the colossal change in android practice movement is that the android is not restricted framework which means that people can make changes according to his own. The paper will portray the real thought of the undertaking android voting structure on android systems and its motivations of interest, loads what's more, applications. Countries all over the world are looking electronic voting[1], for it impacts them not to use uncommon paper for the vote, add the assurance of safety during vote casting, in precision checking and separate each candidate votes, decisions to sort out voting process in a concentrated and distributed way.

This paper proposed the Online voting design with secure customer endorsement by using thumb impression, watchword security, on a very basic level through meeting of mystery keys and image of a person. [2]. This paper proposed e-voting structure which save the distinguishing proof of the person who votes using android compact through face affirmation systems and after that OTP thought is used for sending passwords to people adaptable [3]. This paper proposed framework that utilizations unique mark upheld impression of thumb control data and encryption alongside SSL utilizing VeriSign, make the product associated with the voting procedure very much secured. Additionally, they attempted the tribute to a cell phone will make the framework significantly more enthusiastic [4]. Moreover using the distributed database there will display the areas with voters in it so that voter can only see the candidates of their area only. 
2. Literature review. In many countries polling system is using the world global wide technology, i.e. GSM [5], it presents the electronic voting system using Global System for Mobile Communication. Whenever person cast a vote regarding any event, then post a message to the modem of the global communication system. It contains the voter's cell phone id and unique identity, i.e. its CNIC and then system receives the choice of voter to cast vote against the candidate, after casting vote the process ends. Process of casting votes in the intelligent devices is done through the finger impression [6], gives opportunity to send their vote through the internet by face, finger identification and identity card information. It then take out the relative record form the dataset they have in their system. In this type of casting own choice in election [7], changes the color of the image of the person who make his choice with the national identity code if the verification is valid the he has access to chooses a candidate and put his contribution in the success of candidate.

An Internet voting report named NFS [8] demonstrates the practicality of various kinds of Internet voting from both the specialized and sociology prospects, and characterizes an exploration intend to look for it if Internet voting is to be conceivable later on. In short remote voting frameworks divided into 3 noteworthy classifications given below:

$>$ Cast vote through website: It gives accommodation and effectiveness to voters one might say that the ballot caster make their choice from any survey website, and the counting procedure would be both quick and certain. The significant advantage of this sort of voting framework is that the voting stage and voting condition is possible and secure under organization.

$>$ Kiosk voting: In this type of voting system the voting machines are placed far from the main polling booth like ATM machines of a bank are placed in schools, universities or other public places. The problem begin here is of security (elections Officials have to check them either by cameras or by visiting there).

$>$ Internet voting from far places: It seems to give the most convenience and attractiveness to voter to cast ballot from any location where the internet is accessible.

The electronic voting report of election held in California [9] proposes an approach progressive change towards accomplishing the intension of giving voters the chance to enlist their tallies at whenever from any place by means of the cyberspace. In the report it shows four diverse online voting strategies - online voting at ballot caster inspect corner, online voting from every surveying stall, online vote casting from polling booths, online vote casting from any internet organization, comparing specialized and plan necessities that should be in good while executing at any time at the certain point. It make attention to the focal points, execution and security conflicts of each of the four parts of the process. It ensured that expanded high expert changes are vital before online vote casting can be complete like a valuable framework which enhance in enter into result procedure. That present innovation, however, would take into consideration the usage of new online vote casting process that ensure the balloter to cast vote from any personal computer on internet which is under supervision of Officials.

3. Survey. We do a survey in Pakistan regarding the current election system in the country. Total 928 people participated in the survey. In which there were 515 male and 413 female. Below is the description of different questions in the bar chart form. 


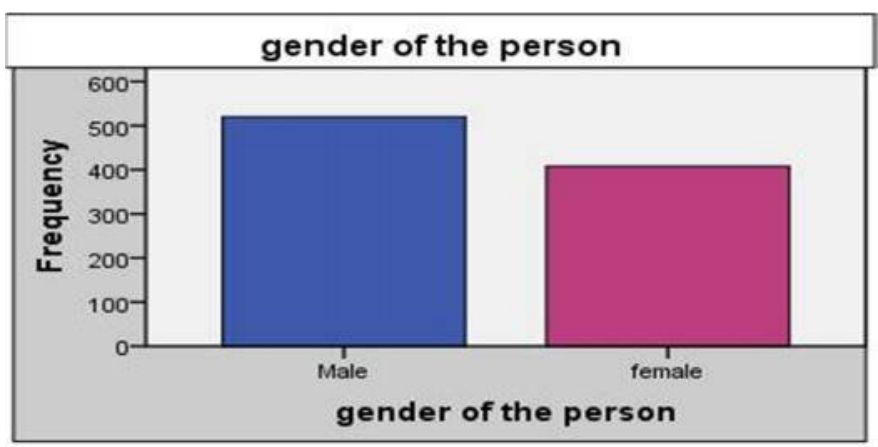

Figure-1: Survey showing the male and female participants.

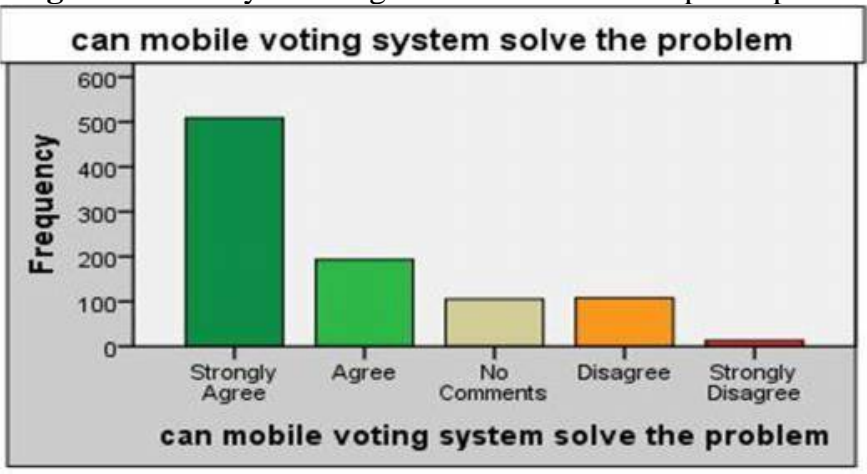

Figure-2: Survey showing Mobile Voting can solve problem.

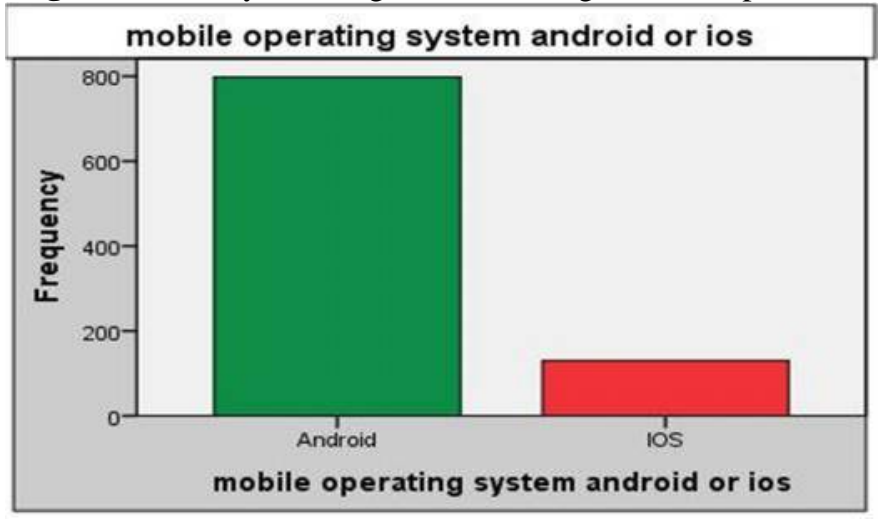

Figure-3: Survey showing people with Android and IOS.

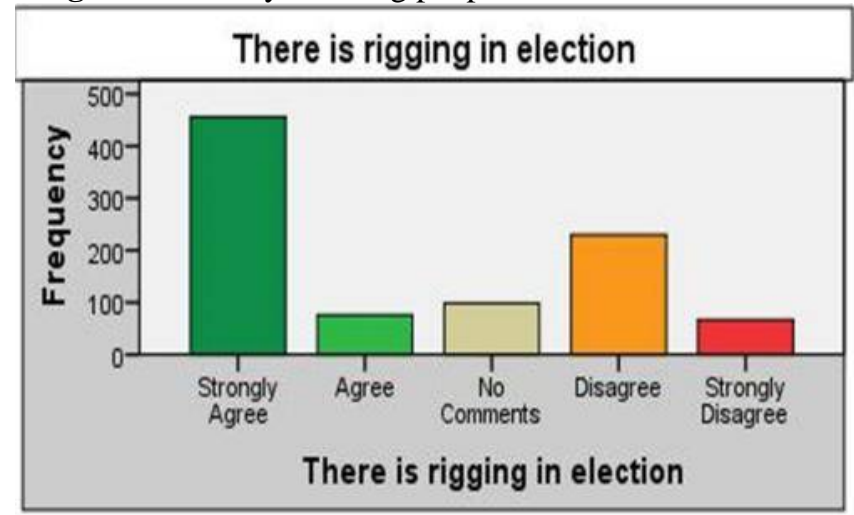

Figure-4: Survey show people view about rigging in election. 


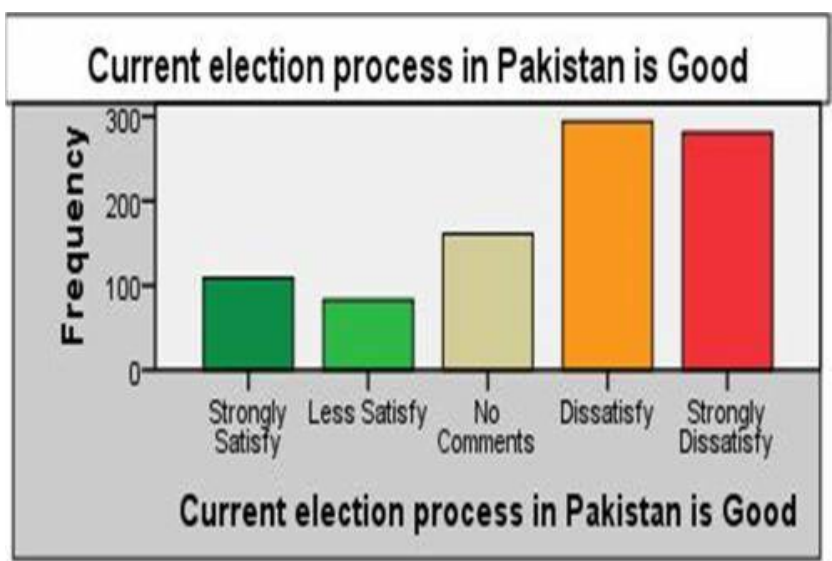

Figure-5: Survey show people view about current election process.

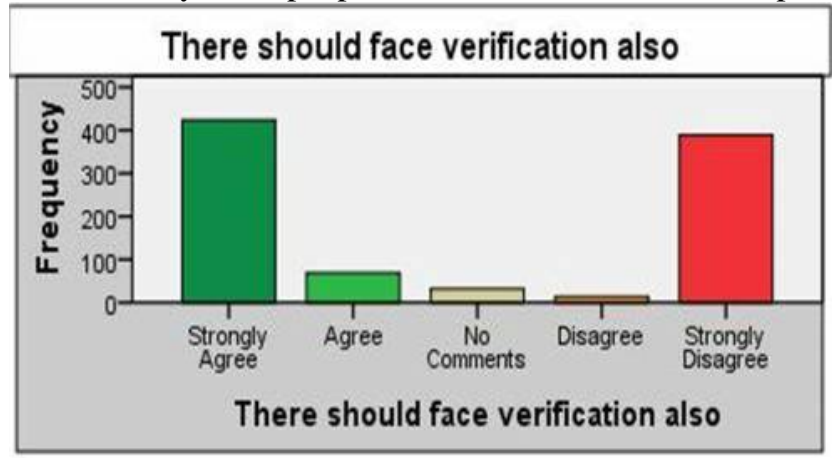

Figure-6: Survey showing people votes about Face Verification.

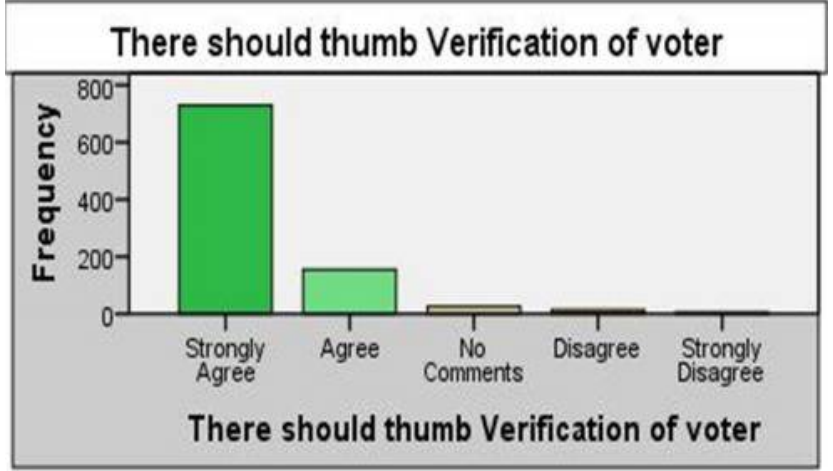

Figure-7: Survey showing people votes about Thumb verification.

4. Proposed system. The purposed system is based on Android operating system, with the existence of programmable smart phones it is not difficult to make an application which will break all records of popularity and give maximum advantage by make use of digital vote casting system. ITU [10], survey that in 2009 approximately four point nine billion smart phones occur and in 2010 this will increase up to five billion. This new scheme of vote casting through android system involves the computerized national identity card number and the one secret key which is given to the voter when he receive his identity card by the national institute.

To login he need CNIC and password if it is correct enter then the picture of face and impression of finger is sized through camera and after that match it with NADRA dataset then allow vote caster to ballot if confirmation process is true. Once the vote is cast then vote casting screen will disappear and ballot casting screen will become disable for the whole day till the election result declare on screen and the election event comes end. The total no of vote of an area (NA/PA) seats will show on voting app at the time of result declaration. 


\section{Experimental design:}

$>$ Working flow

- When user open the e-voting app it show two panels i.e. Admin and Voter

- Admin CURD the candidate information and view the results.

- Voter open his panel by entering his CNIC, phone number and password given at time of registration.

- With giving thumb impression.

- Face recognition

- OTP (One Time Password) is deliver to mobile of balloter. Then attestation of user will check.

- If balloter's password, his look and finger impression is perfectly as it is with the record of person in the dataset.

- Then, according to an area of voter respective candidates will show to voter.

- Voter can see list of candidate and cast vote.

- After that vote of a person will be casted and person account is logged out with in $15 \mathrm{sec}$ after casting vote.

- That voter will not be allowed to vote again.

- At the end result will be declare by the admin.

$>$ One time password: A one-time password (OTP) is a password that is valid for only one login session or transaction. OTPs avoid a number of shortcomings that are associated with traditional (static) password [11].

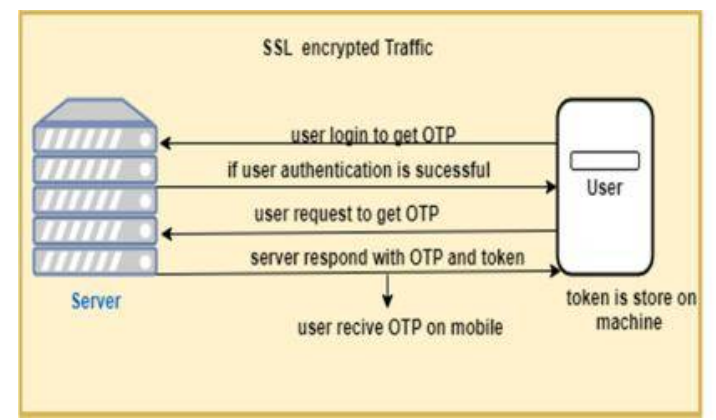

\section{Algorithms}

Figure-8: Shows the process of getting OTP.

- Face recognition: It is helpful in making the voter authenticity and secure system.

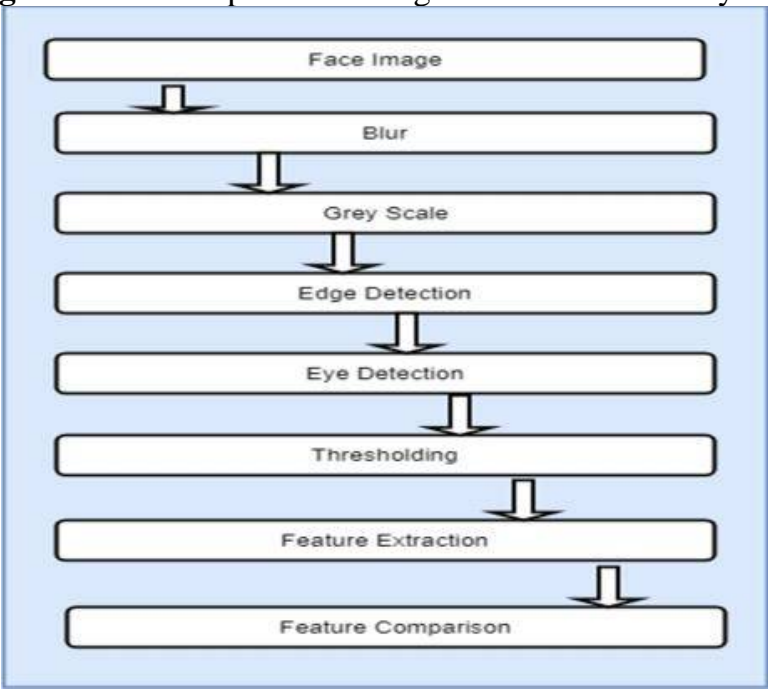

Figure-9: Face verification process. 
- Message digest 5: It is a most commonly algorithm which used cryptanalysis technique i.e. hash function producing a sixteen bits value, which is shown in simple text type as thirty-two digits sixteen's power number [12].This algorithm is used on very large scale in secure information changing and make sure that data has no redundancy [13-17].

- Thumb impression: Unique mark acknowledgment is the most developed approach among all the biometric strategies at any point found. With its achievement of utilization in various applications, it is today utilized as a part of many entrance management application operations as every person has a permanent, interesting particular mark. The skin of the human hand or fingers comprises of purported grating edges with pores. The edges are as of now made in the ninth seven day stretch of a person's fetal improvement life, and continues as before throughout the entire life, just growing up to grown-up measure, however, in the event that extreme wounds happen the skin might be reproduced the same as some time recently. Specialists have discovered that indistinguishable twins have fingerprints that are very unique and that in the criminological group it is trusted that no two individuals have a similar unique mark.

\section{Methodology.}

> Frustrated full domestic reflection (FTIR): Figure below shows how from the lower place of the prism the emulated indicator has gotten by a camcorder when the top place of the prism to get in contact with the human finger. The picture of the finger, which get the space of one by one inch is replaced into five hundred dots per inches using either complementary metal oxide semiconductor (CMOS) camera or charge coupled device. (CCD).

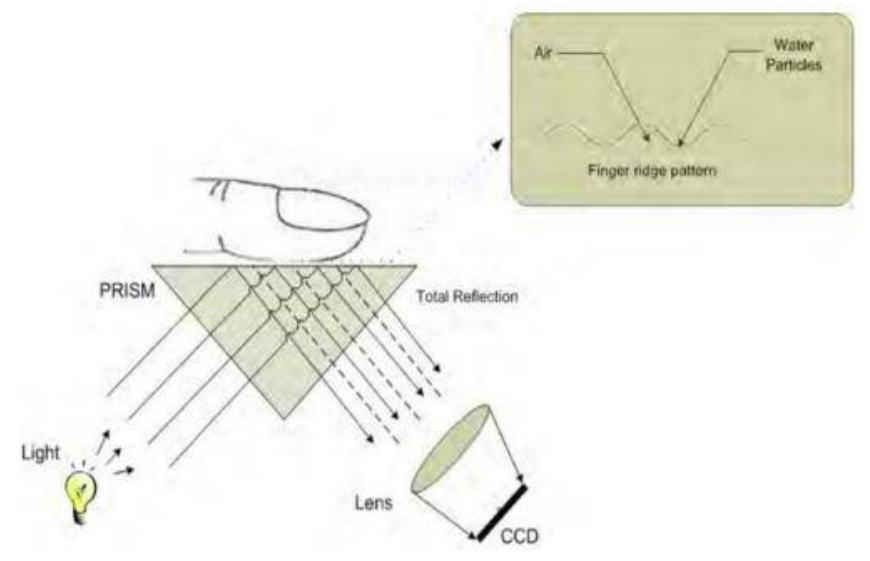

Figure-10: Thumb scanning process.

\section{Some pictures of voting process:}

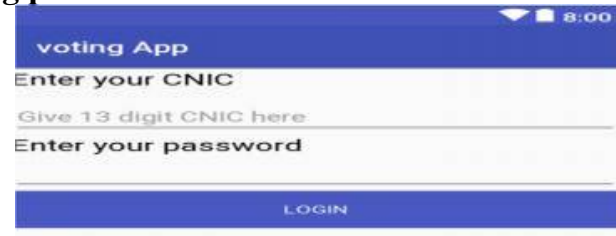

4

Figure-11: Enter CNIC and Password. 


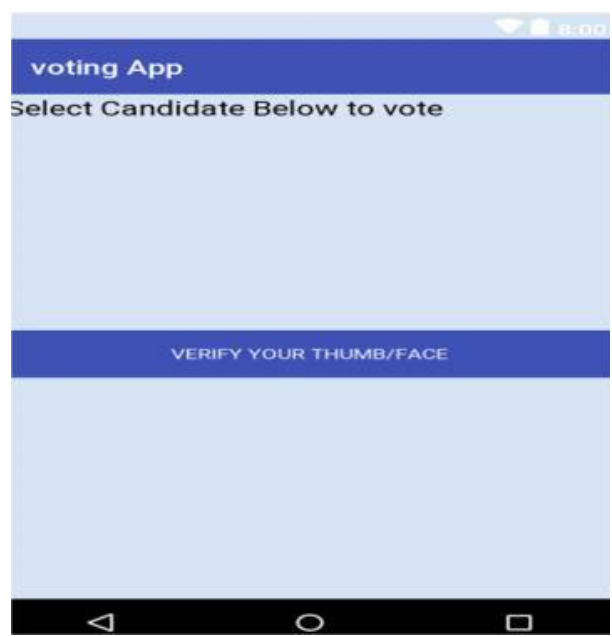

Figure-12: List of candidates in area displayed to voter.

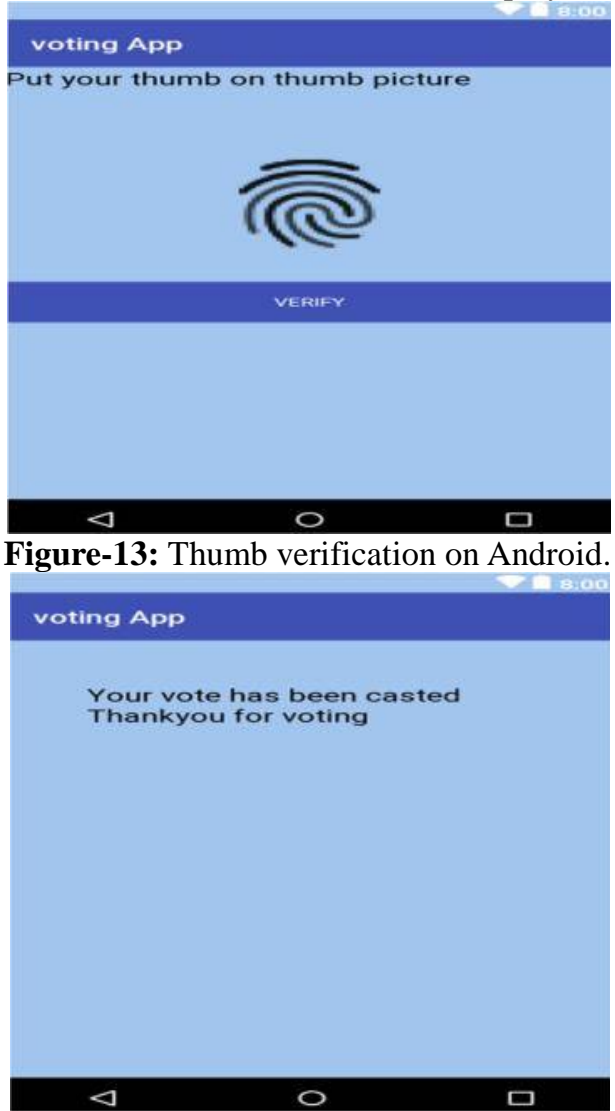

Figure-14: After vote cast user logout automatically.

There is most important thing is that in this voting process each voter can only see the list of candidates of the area where his vote is register. He cannot cast vote for other area candidate.

5. Conclusion. Where there are many advantages of android voting like any event base voting can be done by this there are disadvantages like device dependency or application may not run due to system constrain or other App cause problem. But if this system is built for an election purpose in Pakistan there will be fair election and every one will be satisfied with the result which reduce or end pro-election problems. Pakistan will go on the way of progress rather than remain in the conflict of win of this party or that. 


\section{REFERENCES}

[1] Krimmer, R. (2006). Electronic voting. In Proceedings of the 2nd Workshop on Electronic Voting (ed). Bonn.

[2] Swaminathan, B., \& Dinesh, J. C. D. (2012). Highly secure online voting system with multi security using biometric and steganography. International Journal of Advanced Scientific Research and Technology, 2(2), 195-203.

[3] Mandavkar, A. A., \& Agawane, R. V. (2015, June). Mobile based facial recognition using OTP verification for voting system. In Advance Computing Conference (IACC), 2015 IEEE International (pp. 644-649). IEEE.

[4] Autade, K., Ghadge, P., Kale, S., Kulkarni, N. J., \& Mujgond, S. S. (2012). E-voting on Android System. International Journal of Emerging Technology and Advanced Engineering, 2(2), 242-245.

[5] Sahu, H., \& Choudhray, A. (2011). Polling System Using GSM Facility. International Journal of Scientific \& Engineering Research, 2(10), 1.

[6] Patel, T., Chokshi, M., \& Shah, N. (2013). Smart Device Based Election Voting System Endorsed through Face Recognition. International Journal of Advance Research in Computer Science and Software Engineering, 3(11).

[7] Hegde, G. P., \& Seetha, M. Real Time Voting System Using Face Recognition for Different Expressions and Pose Variations. IJRET: International Journal of Research in Engineering and Technology.

[8] Internet Policy Institute, University of Maryland, \& College Park. (2001). Report of the National Workshop on Internet Voting: issues and research agenda. Internet Policy Institute.

[9] Jones, B. (2000). A report on the feasibility of Internet voting. California Internet Voting Task Force, Sacramento, USA.

[10] Meida, H., Guifa, T., Chunshan, W., \& Guandong, G. (2013, October). Research of Identity Authentication of the Mobile Terminal Voting System. In Intelligent Information Hiding and Multimedia Signal Processing, 2013 Ninth International Conference on (pp. 198-201). IEEE.

[11] Khan, A. A. (2013). Preventing phishing attacks using one time password and user machine identification. arXiv preprint arXiv:1305.2704.

[12] den Boer, B., \& Bosselaers, A. (1993, May). Collisions for the compression function of MD5. In Workshop on the Theory and Application of of Cryptographic Techniques (pp. 293-304). Springer, Berlin, Heidelberg.

[13] Hussain, M., Zaidan, A. A., Zidan, B. B., Iqbal, S., Ahmed, M. M., Albahri, O. S., \& Albahri, A. S. (2018). Conceptual framework for the security of mobile health applications on android platform. Telematics and Informatics, 35(5), 1335-1354.

[14] Hussain, M., Al-Haiqi, A., Zaidan, A. A., Zaidan, B. B., Kiah, M., Iqbal, S., ... \& Abdulnabi, M. (2018). A security framework for mHealth apps on android platform. Computers \& Security, 75, 191-217.

[15] Zaidan, B. B., Haiqi, A., Zaidan, A. A., Abdulnabi, M., Kiah, M. M., \& Muzamel, H. (2015). A security framework for nationwide health information exchange based on telehealth strategy. Journal of medical systems, 39(5), 51.

[16] Hussain, M., Al-Haiqi, A., Zaidan, A. A., Zaidan, B. B., Kiah, M. M., Anuar, N. B., \& Abdulnabi, M. (2016). The rise of keyloggers on smartphones: A survey and insight into motion-based tap inference attacks. Pervasive and Mobile Computing, 25, 1-25.

[17] Woerner, J. J. (1999). Virtual Field Trips in the Earth Science Classroom.Ehsan, A., Mahmood, K., Khan, Y. D., Khan, S. A., \& Chou, K. C. (2018). A novel modeling in mathematical biology for classification of signal peptides. Scientific reports, 8(1), 1039." Khan, Y. D., Ahmad, F., \& Anwar, M. W. (2012). A neuro-cognitive approach for iris recognition using back propagation. World Applied Sciences Journal, 16(5), 678-685.

[18] Khan, Y. D., Khan, S. A., Ahmad, F., \& Islam, S. (2014). Iris recognition using image moments and k-means algorithm. The Scientific World Journal. 